\title{
AUDIT SISTEM LAYANAN KREDIT USAHA RAKYAT (KUR) DENGAN KERANGKA KERJA COBIT
}

\author{
Muji Suwarno \\ $\mathbf{1 5 5 1 0 0 0 5 1 , 9 8 2 8 8 2}$ \\ Fakultas Komputer \\ mujisuwarno-student@umitra.ac.id
}

\begin{abstract}
Perusahaan Umum Jaminan Kredit Indonesia menyetujui dilakukannya audit sistem informasi untuk menemukan permasalahan yang terjadi pada proses kerja layanan KUR.

Audit sistem informasi layanan KUR memiliki ruang lingkup kerangka kerja COBIT yang yang pelaksanaanya di mulai dengan penyebaran Kuisioner untuk penelitian pada pihak - pihak terkait . Audit Sistem Informsai ini di lakukan untuk menemukan permasalahan yang terjadi pada tahap perencanaan sistem, pengumpulan data primer dan skunder.
\end{abstract}

Kata Kunci : Audit sitem informasi, cobit 
A. PENDAHULUAN

Materi Kuliah Membahas

Tentang Audit sistem informasi study kasus Resume audit perusahaan KUR.

Menganalisa sistem layanan kredit usaha rakyat, pemeriksaan lapangan, pelaporan, dan tidak lanjut.

\section{B. PEMBAHASAN / STUDI KASUS}

Resume Section VIII ini membahas tentang studi kasus tentang Audit perusahaan pada Kredit Usaha Rakyat (KUR).

Menemukan permasalahan pada proses kerja layanan KUR pada tahap perencanan sistem, auditor pengumpulan data primer dan skunder seperti hasil kuisioner, data nasabah, ktp, surat ijin usaha, surat riwayat mengambil KUR, form pengajuan KUR dll.

Menganalisa sistem layanan Kredit Usaha Rakyat (KUR) yang sendang berjalan dengan menggunakan alur flow chart.

Analisa sistem tersebut telah menemukan kelemahan pada sistem KUR yaitu sering di temukannya kredit macet oleh nasabah bank dikarnakan kurangnya analisa kelayakan yang tepat dalan pemberian ACC pengajuan KUR terkait data usaha nasabah.

Pemeriksaan lapangan (fieldwork) di lakukan dengan beberapa tahap : Pemeriksaaan data dan bukti, kuisioner, hasil pengolahan data kuisioner,

Pelaporan (reporting) yaitu setelah kuisioner disebarkan maka akan di dapat data yangakan di proses untuk di hitung berdasarkan perhitungan maturity level.

Setelah semua tahap di lakukan maka tahap selanjutnya adalah tindak lanjut ( follow up) yang selanjutnya di lakukan riview oleh manajemeh sehingga menjadikan audit ini sebagai acuan untuk mengembangkan sistem informasi layanan KUR.

\section{ID SECURITY QWTD4452377-ASP-5244107}

\section{KESIMPULAN}

Audit sistem informasi layanan KUR memiliki ruang lingkup kerangka kerja COBIT yang yang pelaksanaanya di mulai dengan penyebaran Kuisioner untuk penelitian pada pihak pihak terkait . Audit Sistem Informsai ini di lakukan untuk menemukan permasalahan yang terjadi pada tahap perencanaan sistem, pengumpulan data primer dan skunder.

\section{E. DISKUSI}

Saya bersama teman saya bernama oky mendiskusikan 
tentang Audit perusahaan ini dengan sangat baik Hasil diskusi dari materi ini adalah Dengan di lakukannya audit perusahaan dengan metode COBIT maka bisa di ambil kesimpulan bahwa setelah di lakukan riview hasil audit tersebut bisa menjadi acuan untuk mengembangkan sistem informasi layanan KUR.

\section{F. REFERENCE}

[1] O. M. Febriani and A. S. Putra, "Sistem Informasi Monitoring Inventori Barang Pada Balai Riset Standardisasi Industri Bandar Lampung," J. Inform., vol. 13, no. 1, pp. 90-98, 2014.

[2] A. S. Putra, "Paperplain: Execution Fundamental Create Application With Borland Delphi 7.0 University Of Mitra Indonesia," 2018.

[3] A. S. Putra, "2018 Artikel Struktur Data, Audit Dan Jaringan Komputer," 2018.

[4] A. S. Putra, "ALIAS MANAGER USED IN DATABASE DESKTOP STUDI CASE DB DEMOS."

[5] A. S. Putra, "COMPREHENSIVE SET OF PROFESSIONAL FOR DISTRIBUTE COMPUTING."

[6] A. S. Putra, "DATA ORIENTED RECOGNITION IN BORLAND DELPHI 7.0.”

[7] A. S. Putra, "EMBARCADERO DELPHI XE 2 IN GPUPOWERED FIREMONKEY APPLICATION."
[8] A. S. Putra, "HAK ATAS KEKAYAAN INTELEKTUAL DALAM DUNIA TEKNOLOGY BERBASIS REVOLUSI INDUSTRI 4.0."

[9] A. S. Putra, "IMPLEMENTASI PERATURAN PERUNDANGAN UU. NO 31 TAHUN 2000 TENTANG DESAIN INDUSTRI BERBASIS INFORMATION TECHNOLOGY."

[10] A. S. Putra, "IMPLEMENTATION OF PARADOX DBASE."

[11] A. S. Putra, "IMPLEMENTATION OF TRADE SECRET CASE STUDY SAMSUNG MOBILE PHONE."

[12] A. S. Putra, "IMPLEMENTATION PATENT FOR APPLICATION WEB BASED CASE STUDI WWW. PUBLIKLAMPUNG. COM."

A. S. Putra, "IMPLEMENTATION SYSTEM FIRST TO INVENT IN DIGITALLY INDUSTRY."

[14] A. S. Putra, "MANUAL REPORT \& INTEGRATED DEVELOPMENT

ENVIRONMENT BORLAND DELPHI 7.0.”

[15] A. S. Putra, "PATENT AS RELEVAN SUPPORT RESEARCH."

[16] A. S. Putra, "PATENT FOR RESEARCH STUDY CASE OF APPLE. Inc.”

[17] A. S. Putra, "PATENT PROTECTION FOR APPLICATION INVENT."

[18] A. S. Putra, "QUICK REPORT 
PROPERTY PROGRAMMING."

A. S. Putra, "REVIEW CIRCUIT LAYOUT COMPONENT REQUIREMENT ON ASUS NOTEBOOK."

[20] A. S. Putra, "REVIEW TRADEMARK PATENT FOR INDUSTRIAL TECHNOLOGY BASED 4.0."

[21] A. S. Putra, "TOOLBAR COMPONENT PALLETTE IN OBJECT ORIENTED PROGRAMMING."

[22] A. S. Putra, "WORKING DIRECTORY SET FOR PARADOX 7."

[23] A. S. Putra, "ZQUERY CONNECTION

IMPLEMENTED

PROGRAMMING STUDI CASE PT. BANK BCA Tbk."

[24] A. S. Putra, D. R. Aryanti, and I. Hartati, "Metode SAW (Simple Additive Weighting) sebagai Sistem Pendukung Keputusan Guru Berprestasi (Studi Kasus: SMK Global Surya)," in Prosiding Seminar Nasional Darmajaya, 2018, vol. 1, no. 1, pp. 85-97.

[25] A. S. Putra and O. M. Febriani, "Knowledge Management Online Application in PDAM Lampung Province," in Prosiding International conference on Information Technology and Business (ICITB), 2018, pp. 181-187.

[26] A. S. Putra, O. M. Febriani, and B. Bachry, "Implementasi Genetic Fuzzy System Untuk Mengidentifikasi Hasil Curian Kendaraan Bermotor Di Polda
Lampung," SIMADA (Jurnal Sist. Inf. dan Manaj. Basis Data), vol. 1, no. 1, pp. 21-30, 2018.

[27] A. S. Putra, H. Sukri, and K. Zuhri, "Sistem Monitoring Realtime Jaringan Irigasi Desa (JIDES) Dengan Konsep Jaringan Sensor Nirkabel," IJEIS (Indonesian J. Electron. Instrum. Syst., vol. 8, no. 2, pp. 221-232.

[28] D. P. Sari, O. M. Febriani, and A. S. Putra, "Perancangan Sistem Informasi SDM Berprestasi pada SD Global Surya," in Prosiding Seminar Nasional Darmajaya, 2018, vol. 1, no. 1, pp. 289-294. 